International Review of Research in Open and Distributed Learning Volume 16, Number 4

October - 2015

\title{
Exploring the Roles of Social Participation in Mobile Social Media Learning: A Social Network Analysis
}

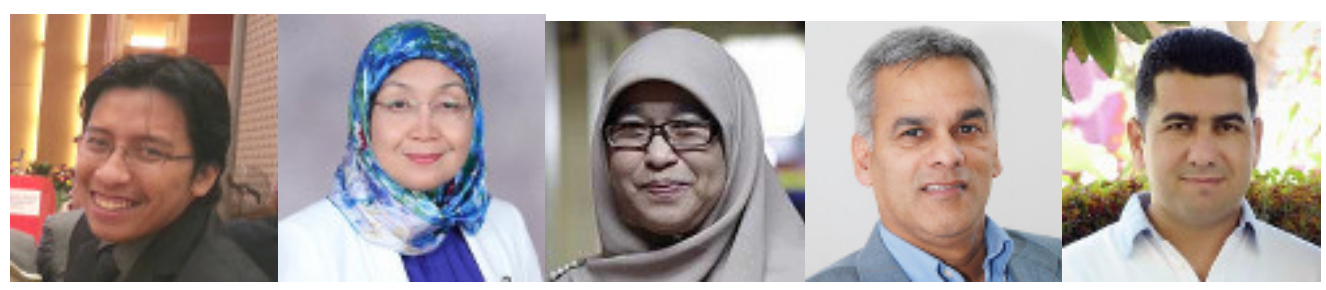

Helmi Norman ${ }^{1,2}$, Norazah Nordin2, Rosseni Din2, Mohamad Ally ${ }^{3}$, and Huseyin Dogan ${ }^{1}$

${ }^{1}$ Bournemouth University, United Kingdom, ${ }^{2}$ National University of Malaysia, ${ }^{3}$ Athabasca University, Canada

\begin{abstract}
Social media is increasingly becoming an essential platform for social connectivity in our daily lives. The availability of mobile technology has further fueled its importance - making it a ubiquitous tool for social interaction. However, limited studies have been conducted to investigate roles of social participation in this field. Thus, the study investigates roles of social participation in mobile social media learning using the "ladder of participation and mastering." Participants were students taking an educational technology course in a local university. The study was conducted in a four-month period. Data was collected from discussions while learning among the students a social media platform, Facebook groups, on mobile devices. The data was analyzed using a social network analysis tool, NodeXL. Data was analyzed based on egocentric networks, betweeness centrality, and closeness centrality. The findings revealed that there are four roles of social participation in mobile social media, which are: (i) lurkers; (ii) gradually mastering members/ passive members; (iii) recognized members; and (iv) coaches. The findings also indicated that over the course of four months, learners can inter-change roles of social participation - becoming more central or less central in learning discussions. As a result, a roles of social participation continuum for mobile social media learning is proposed. Future research could be conducted in other fields to investigate whether the continuum produced could be used to understand the relationship between mobile social media learning and social participation roles.
\end{abstract}


Keywords: Roles in social participation, mobile social media learning, ladder of participation and mastering, community of practice, social network analysis, NodeXL

\section{Introduction}

Social media is becoming a ubiquitous platform for social interaction in our daily lives (Siemens \& Weller, 2011; Chin \& Zhang, 2014). The explosion of social media has led to numerous research by educators to tap and seek into the potential of social media for learning (Aadal, Kirkevold, \& Borg, 2013; Ally \& Samaka, 2013; Norman, Din, Nordin, \& Ryberg, 2014). Although learners are constantly on the move, social media allows them to stay connected to their peers in digital social interaction spaces via mobile devices (Chen \& Bryer, 2012; Dabbagh \& Kitsantas, 2012; Chin \& Zhang, 2014). The connectivity of mobile learners that learn using social media on mobile devices is termed "mobile social media learning" (Lewis, Pea, \& Rosen, 2010; Multisilta, 2012; Chin \& Zhang, 2014). Mobile social media learning is changing the way we understand the term "participation" in a learning community (Lewis et al., 2010; Chin \& Zhang, 2014). Although much work has been done in understanding participation in social media, fewer studies have focused on investigating participation of learning in mobile social media where learners are mobile and use social media on mobile devices (Lewis et al., 2010; Gikas \& Grant, 2013). This presents an opportunity to explore social participation learning in the area of mobile social media learning. Thus, the study investigates the roles of social participation in mobile social media learning.

The paper is organized as follows. First, the concepts applied in this study such as "mobile social media learning", "roles of social participation", and "ladder of participation and mastering" are introduced. These concepts are then linked with recent literature to illustrate the research gap identified. It is followed by a discussion on the research approach and methods used to capture and analyze the data via social network analysis. This paper concludes with a discussion on the findings as well as implication and future directions in the area of mobile social media learning.

\section{Mobile Social Media Learning and Roles of Social Participation}

The terms "mobile social media learning" originates from the terms "mobile learning" and "social media" and illustrates a situation where learners are involved with the process of learning using social media on mobile devices (Chen \& Bryer, 2012; Dabbagh \& Kitsantas, 2012; Chin \& Zhang, 2014). Social media is associated with online social platforms such as social network sites, blogs, microblogs, photo/video sharing sites, and location-based services. These platforms allow for interaction and communication between users and allow them to create and share content with each other via digital devices (Bechmann and Lomborg, 2013).

This work is licensed under a Creative Commons Attribution 4.0 International License. 
The definition of mobile learning can be viewed from two perspectives, which are: "the mobile learner perspective" and "the mobile learning tools perspective." In this study, we define mobile learning according to the first perspective where we investigate "mobile" as the "mobile" state of the learner rather than the "mobile" learning tools. This is line with the views of Sharples, Taylor, \& Vavoula (2010), Kukulska-Hulme (2010), and Wong (2012) that define mobile learning in relation to the "mobility" state of learners in which they can access their personalized learning environment as they physically move (Kukulska-Hulme 2010; Wong, 2012). Moreover, scholars also suggest that as learners are on the move, they experience diverse learning situations in which their learning changes from one context to another, for instance from formal to informal learning (J eng, Wu, Huang, Tan, \& Yang 2010; Wong, 2012). In contrast, some scholars view mobile learning as learning that occurs on mobile technologies or mobile devices, which could affect learning due to small screen sizes of the tools (Cochrane \& Bateman 2010; Liu, Lin, Tsai, \& Paas, 2012). However, in this study, we lay more emphasis on the learning state of the mobile learner and do not focus on the "learning tool" or "learning device" factor towards mobile learning. As such, it is worth to note that the term "mobile device" in this study covers "portable learning technologies" which the learners bring usually bring with them, such as smartphones, tablet PCs, notebooks, and laptops.

Recent literature suggests that research in mobile social media learning is relatively new (Bechmann and Lomborg, 2013). Studies in this filed include studies by Gikas and Grant (2013) and Pimmer, Linxen, \& Gröhbiel, (2012). In Gikas and Grant's (2013) study, they investigated students' perception of social media learning usage on mobile devices. Findings of their study revealed that students perceived that mobile social learning could assist them in terms of accessing information quickly, enhance communication between classmates and instructors, as well as offer situated and contextualized learning. Findings also indicated that students had issues with mobile devices which led to frustration and issues with devices as a distraction (i.e. mobile devices causing them to be distracted with activities not associated with learning such as instant messaging among classmates). As for Pimmer et al.'s (2012) work, they studied the use of social media on mobile phones. The study was conducted in the medical field with students and professionals of developing countries. Results revealed that social media on mobile phones had a positive impact on informal learning where students and professional were engaged in informal learning activities such as sharing of cartoon images related to the medicine.

Although there have been recent studies conducted in mobile social media learning such as Gikas and Grant's (2013) and Pimmer et al.'s (2012) research, there are very few studies that focus on roles of social participation in this field (Pimmer et al., 2012; Bechmann \& Lomborg, 2013). Social participation in learning is commonly associated with students' participation during academic activities; for example participation of a student in organized learning task and the "social engagement" with peers and instructors (Caspi, Chajut, Saporta, \& Beyth-Marom, 2006). In mobile social media learning, the social participation concept is quite different in a sense that students and instructors are connected online rather than face-to-face. This causes the roles of social participation to slightly differ from face-to-face environments (Pimmer et al., 2012;

This work is licensed under a Creative Commons Attribution 4.0 International License. 
Bechmann and Lomborg, 2013). As such, we attempt to fill the gap by investigating roles of social participation in mobile social media learning.

\section{Situated Learning, Community of Practice, and the Ladder of Participation and Mastering}

The study uses the concepts of "situated learning" and "community of practice" as the underlying concepts and applies the "ladder of participation and mastering" as the research scale for social media analysis. Before discussing the research scale used, the concepts of "situated learning" and "community of practice" are discussed. The situated learning theory was introduced by Lave and Wenger (1991). The theory posits that learning involves a process of social participation rather than knowledge acquisition by individual learners. The theory also regards that the "situation" or "context" in which learning takes place is a crucial element that impacts the process of learning (Lave \& Wenger, 1991; Naismith, Sharples, Vavoula, \& Lonsdale, 2004). In other words, the situated learning theory defines the learning process to exist when a learner is involved in interaction with members of the community and participates in shared activity in a community (Lave \& Wenger, 1991; Aadal, Kirkevold, \& Borg, 2013). In a community of practice, the "oldtimers" or members who have been a part of a community for a longer period, develop a "shared knowledge bank" of learning experiences, stories, tools, and methods of overcoming recurring learning problems (Wenger, White, \& Smith, 2009; Aadal et al., 2013). The newcomers then join this community to take advantage of this "shared knowledge bank". The learning is described as "towards mastering new understandings" by involvement and participation in new learning activities, as well as carrying new tasks and functions (Lave \& Wenger, 1991; Aadal et al., 2013). The community of practice can further promote engagement of learners with other learners in the learning community, and reach a sufficient level of understanding to participate in learning practices of the community, thus making learning more meaningful (Wenger et al., 2008).

As newcomers attempt to reach the level of "mastering new understandings," a learner would be involved in the concept of "apprenticeship learning" or cognitive apprenticeship. Lave and Wenger (1991) explained that learning always exist in social practices where learners gradually become legitimate members via their participation. In a more recent work, Ryberg and Christiansen's (2008) illustrated the "apprenticeship learning" process via the concept of "ladder of participation and mastering" in a Danish social networking website, as shown in Table 1. In their study, this concept is viewed from the perception that learning in a mobile social environment is achieved by moving up the "ladder of participation and mastering." The concept consists of four stages. In the initial stage, a learner would be in the state of lurking where he/ she observes and identifies what is going on in the environment and gradually mimics the behavior of the community (Ryberg \& Christiansen, 2008). This could be influenced by two factors, which are: social rules of the community (implicit) that the learner has understood by himself/ herself; social rules explicitly laid out by the community; or the combination of both (Ryberg \& Christiansen, 2008). The scenario is linked with the Social Learning Theory by Albert Bandura (1977), where the theory states that learning is a cognitive process that can occur through observation of behavior in a learning environment. For the second stage, a learner would

This work is licensed under a Creative Commons Attribution 4.0 International License. 
gradually master the knowledge in the community. In the third stage, a learner remains intact with the environment increases his/her skills and becomes a recognized member (Ryberg \& Christiansen, 2008). In the final stage, a learner gradually shifts into a feeder of knowledge in the community serving as a coach or a teacher (Ryberg \& Christiansen, 2008).

Table 1

Social Roles Based on the Ladder of Participation and Mastering

\begin{tabular}{cll}
\hline Stage & $\begin{array}{l}\text { Steps in ladder of participation and } \\
\text { mastery }\end{array}$ & Social roles \\
\hline 1 & $\begin{array}{l}\text { Lurking/mimicking } \\
\text { Gradually mastering }\end{array}$ & $\begin{array}{l}\text { Lurker } \\
\text { Gradually mastering } \\
\text { member }\end{array}$ \\
3 & $\begin{array}{l}\text { Being confident with own skills - } \\
\text { becoming a legitimate recognized member } \\
\text { Teaching others and feeding into the } \\
\text { community's collective learning }\end{array}$ & Recognized member \\
4 & Coach \\
\hline
\end{tabular}

Recent literature has indicated that various work has been done in the field of "apprenticeship learning" or cognitive apprenticeship. In medicine, Kopcha and Alger (2014) studied whether technology-enhanced cognitive apprenticeship could be adapted to clinical teaching and learning. Their study revealed that the concept improved the performance scores of students taking the clinical training over a period of a year. In computer science, Knobelsdorf et al. (2013) discovered that cognitive apprenticeship also improved the results of students taking introductory computer science courses in their university. Meanwhile, in the field of education, Kuo et al. (2012) investigated on whether learning styles affected cognitive apprenticeship. They found out that cognitive apprenticeship had a positive impact on the learners which had a field-dependent learning style. However, to date, there are limited studies that have been conducted linking cognitive apprenticeship with mobile social media learning (Zheng et al., 2015). Thus, we utilize the "ladder of participation and mastering" to study roles of social participation in mobile social media learning.

\section{Methodology}

\section{The Research Continuum Applied in the Study}

The study attempted to investigate roles of social participation in mobile social media learning via the ladder of participation and mastering by Ryberg and Christiansen (2008). As such, the ladder was modified to represent the roles of social participation in each stage of the ladder as shown in Table 1 . The role of participation of the lurking/mimicking stage at Stage 1 is

This work is licensed under a Creative Commons Attribution 4.0 International License. 
categorized as the lurker while the gradually mastering stage at Stage 2 is categorized as the gradually mastering member. At Stage 3 (being confident with own skills - becoming a legitimate recognized member), the role is classified as the recognized member. At the final stage, the role is categorized as the coach.

As such, the following research scale was developed to investigate social roles in mobile social media learning. The scale consisted of four roles on a continuum, which are: lurker, gradually mastering member, recognized member, and coach. The continuum is unidirectional, representing a higher participation level or "moving upwards" the ladder of participation and mastering. The research continuum is illustrated in Figure 1.

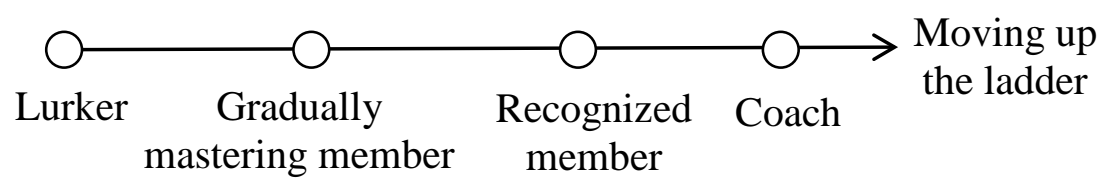

Figure 1. The investigated research scale based on the "ladder of participation and mastering."

\section{Data Collection Method}

The data collection method is explained in four sections, which are: (i) participants; (ii) instruction; (iii) learning platform; and (iv) additional learning materials.

Participants. The participants of the study consisted of 30 female students taking an educational technology course in a public university. The course was a four-month foundational course for pre-service teacher trainees to learn effective approaches in information technology (IT) for future teaching purposes. Although the students' level of IT usage for daily activities were high, their level of knowledge on IT usage for teaching was relatively low - they either had little or no background in implementing IT for teaching purposes.

Instruction. The students were given an unstructured (loosely structured) group learning task. Unstructured group tasks are tasks that are loosely structured in terms of learner autonomy over formulation and execution of the learning problem, work process, and solution (Ryberg, Glud, Buus, \& Georgsen, 2010; Park, 2011). In other words, the tasks were designed to give more autonomy towards learners and shift learning from teacher-centered learning to student-directed learning.

As such, each group was assigned to produce a 5-minute video on an open topic using their mobile devices. Students were required to share their videos and discuss/report their progress on a social media platform (i.e. Facebook group) via mobile devices. Students were required to complete the learning task within a 14-week period from October 2013 until J anuary 2014.

This work is licensed under a Creative Commons Attribution 4.0 International License. 
Learning platform. The social media platform, Facebook (FB) Groups, was used as the learning platform. The FB group consisted of all the students and instructors taking the educational course in the semester. The group was set as a "closed group" in which posts can only be seen by the students and instructors that were in the course. Data was collected in terms of comments exchanged among students and instructors.

Additional learning materials. A blog was created to serve as additional reference for students. The blog consisted on topics related to video production such as scriptwriting, storyboarding, video shooting angles, video composition, video camera movements, videoediting, and audio editing.

\section{Data Analysis Method}

The data obtained was analyzed through social network analysis (De Laat, Lally, Lipponen, \& Simons; Hansen, Shneiderman, \& Smith, 2011). Social network analysis allowed investigation and visualization of the roles in mobile social media learning. The four roles of social participation investigated were: (i) lurker; (ii) gradually mastering member; (iii) recognized member; and (iv) coach. In order to investigate these roles, the social networks were studied in two stages of the learning process: the initial stages of the course (the initial four weeks of the 14-week course), and the latter stages (the final four weeks). As such, the following network metrics were analyzed in 1.5 degree FB Group egocentric networks (person-to-person network) in terms of: (i) egocentric network graphs, and (ii) betweeness and closeness centrality. The software used for analysis is NodeXL.

Egocentric network graphs. These type of graphs allowed for visualization of relational data that exist in mobile social media learning. For egocentric networks, positions of edges (dots representing students/instructors) that were more in the center indicated that the student had a high level of participation in the Facebook Group, whereas positions off the center indicated that the student had a low level of participation. In other words, students in the center of the network were more active while students who were off the center were more passive. In this study, directed egonetwork images were created with the Harel-Koren Fast Multiplescale layout (Harel and Koren, 2001; Hansen et al., 2011).

Betweeness centrality and closeness centrality. Centrality is commony used to investigate the role of actors in social networks (Hansen et al., 2011, Ni, Sugimoto, \&J iang, 2011). Closeness centrality refers to the average shortest distance from one vertex to another. The measure can be used to identify how close a person is to other people in the network (Hansen et al., 2011; Ni et al., 2011). In the study, closeness centrality was used to investigate information flow - whether a student could be able to deliver information in relatively fewer steps than others.

This work is licensed under a Creative Commons Attribution 4.0 International License. 
Betweeness centrality is closely related to closeness centrality. When an edge lies on the shortest path between two other edges, the edge has more control over the both the edges' interaction. In other words, a higher level of betweeness and closeness centrality indicates that the student is highly influential in the network (Hansen et al., 2011; Ni et al., 2011).

\section{Results}

\section{Overall Social Network Metrics}

The overall social network metrics during the initial and final four weeks of the course are shown in Table 2 and 3 respectively. Table 2 shows that the total edges for the initial four weeks were 428, and the number of edges increased to 1115 as the course reached the final four weeks. The total vertices also increased as there was an increase of student involvement (an increment of four students) from 30 to 34 vertices.

Table 2

Overall Social Network Metrics for the Initial Four Weeks

\begin{tabular}{lc}
\hline Element & Total \\
\hline Vertices & 30 \\
Unique Edges & 151 \\
Edges With Duplicates & 277 \\
Total Edges & 428 \\
\hline
\end{tabular}

Table 3

Overall Social Network Metrics for the Final Four Weeks

\begin{tabular}{lc}
\hline Element & Total \\
\hline Vertices & 34 \\
Unique Edges & 160 \\
Edges With Duplicates & 955 \\
Total Edges & 1115 \\
\hline
\end{tabular}

\section{Egocentric Network Graphs}

This section displays the results of the egocentric network graphs. Three egocentric network graphs are used in illustrating the scenarios that were identified during the initial and final four

This work is licensed under a $\underline{\text { Creative Commons Attribution } 4.0 \text { International License. }}$ 
weeks of the course. To maintain the anonymousness of the students, the students were referred to as S1 for student 1, while instructors were referred to as I1 for instructor 1 . The findings are as follows:

Lurker to gradually mastering member. From Figure $2 \mathrm{a}$, it can be seen that the position of S10 was outside of the network inferring that the student level of participation in learning discussions among other coursemates was relatively low. The analysis showed a possible pattern of lurking - looking at coursemates but not being involved in the discussions and communication. Thus, S10 is categorized as a lurker in the initial stages of the course.

However, as the course progressed to the final four weeks, S10 shifted roles - from being a lurker to becoming a gradually mastering member. In Figure 2b, it can observed that S10 position has moved into the center of network, where the level of participation was higher.

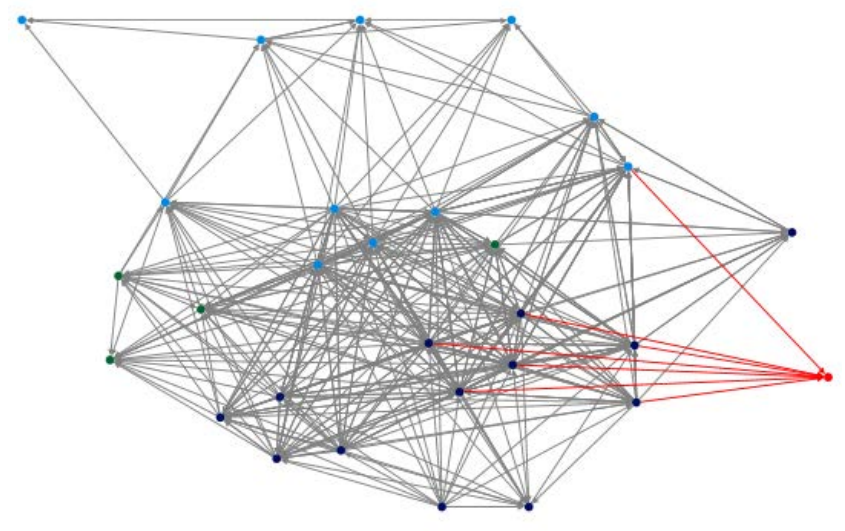

Created with NodeXL (http://nodexl.codeplex.com)

Figure 2a. An egocentric network of a "lurker" (initial four weeks)

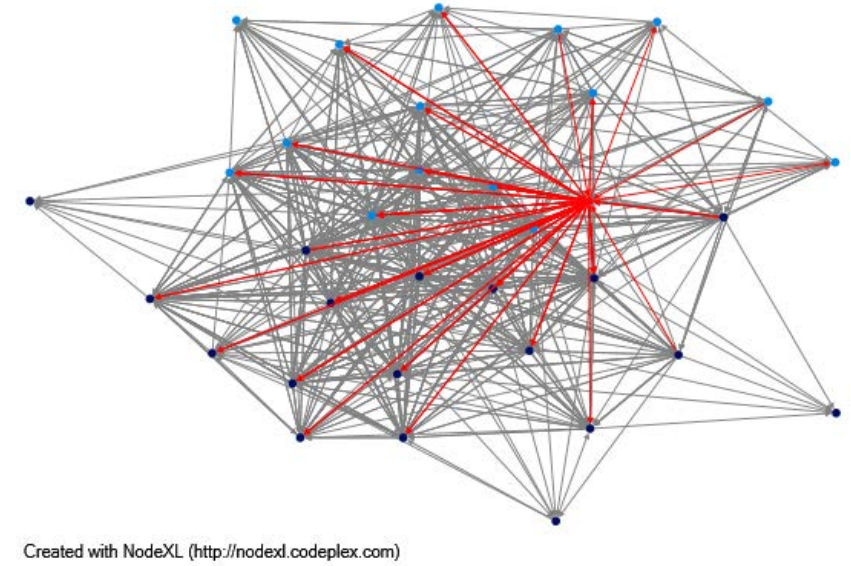

Figure 2b. An egocentric network of "lurker" becoming a "gradually mastering member" (final four weeks)

Gradually mastering member to recognized member. Figure 3a shows the network graph of a gradually mastering member (S5 in the initial four weeks). Here, it can be seen the position of the student is off the center of the graph. As the course entered the final four week period, a shift was observed as S5 moved towards the center of the graph, as illustrated in Figure 3b. This indicated that S5 became more involved with the communication among other students further suggesting that the student changed her role from gradually mastering member to become a recognized member. 


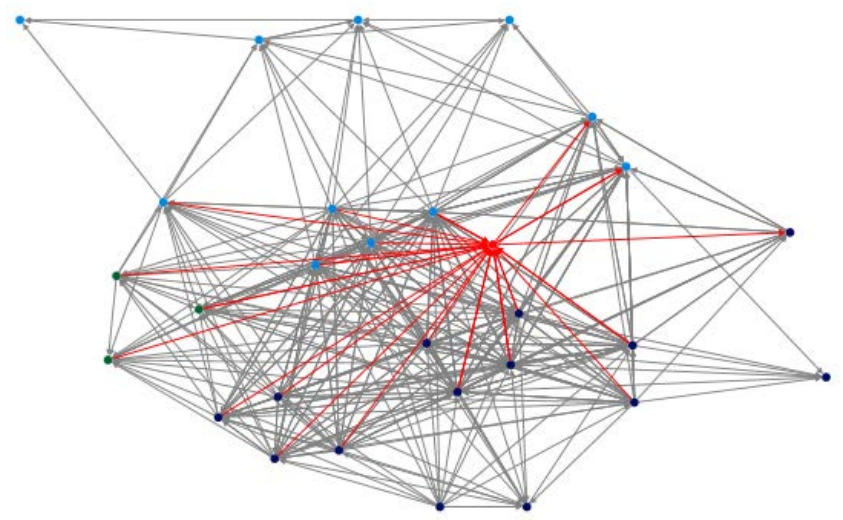

Created with NodeXL (http://nodexl.codeplex.com)

Figure 3a. A egocentric network of a "gradually mastering member" (initial four weeks)

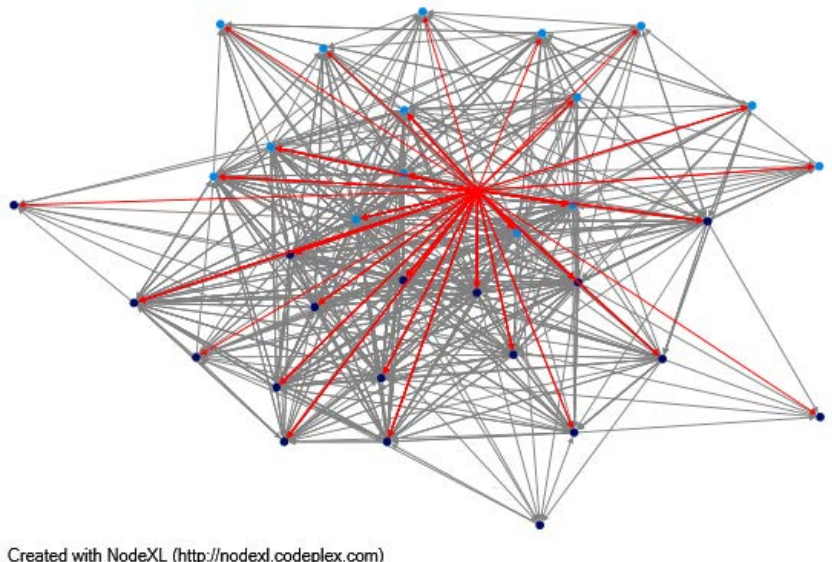

Created with NodeXL (http://nodexl.codeplex.com)

Figure 3b. An egocentric network of "gradually mastering member" becoming a "recognized member" (final four weeks)

A recognized member to passive member. In Figure 4a, a egonetwork graph of recognized member (S18) in the initial four week period is illustrated. As the course progressed into the final four weeks, it was observed that the student's level of communication with the other group members decreased and had a lower social participation level. This indicates that the recognized member became less influential in the learning community and became more passive in terms of participation. We term this as the passive member. In addition, this also further shows that a learner can move both upwards and downwards the "ladder of participation and mastery" depending on his/ her level of social participation in the community.

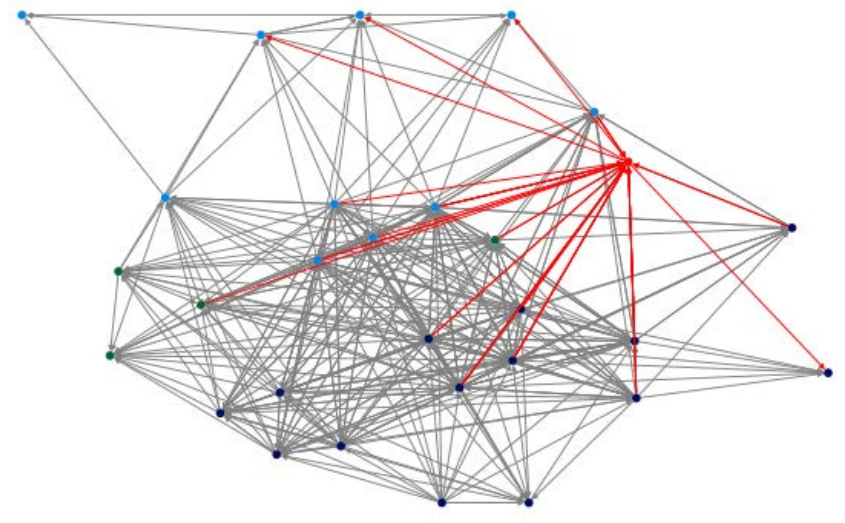

Created with NodeXL (http://nodexl.codeplex.com)

Figure 4a. A egocentric network graph of a "recognized member" (initial four weeks)

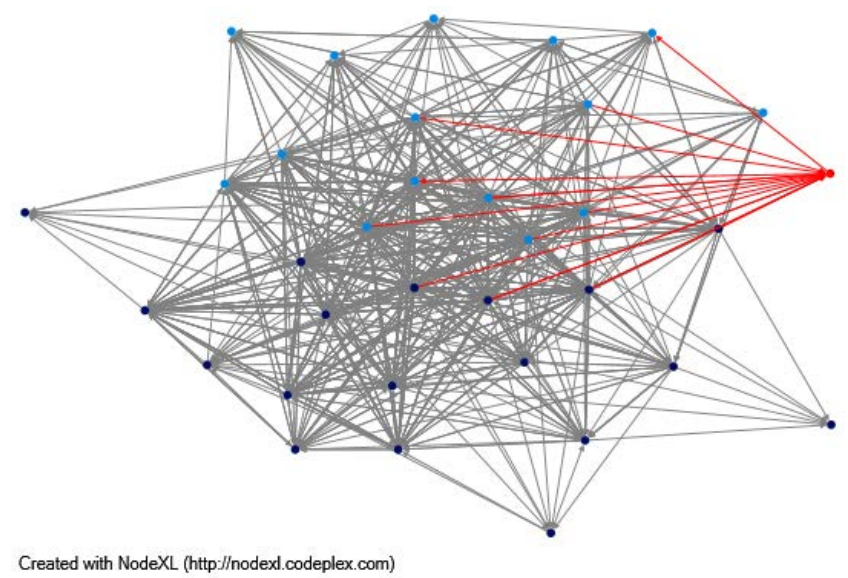

Figure 4b. An egocentric network of a recognized member becoming a "passive member" (final four weeks) 


\section{Betweeness and Closeness Centrality}

The results of betweeness and closeness centrality metrics are displayed in Table 4, and 5 respectively. The egocentric network results showed that there were three shifts of roles: (i) lurker to gradually mastering member for S10; (ii) gradually mastering member to recognized member for S5; and (iii) recognized member to passive member for S18. As such, the results of betweeness and closeness centrality as discussed according to the shift of roles of S10, S5, and S18.

Student 10 (S10). For S10, the betweeness and closeness centrality was 0.000 and 0.020 in the initial four weeks indicating that the student was not active in the online discussions at this particular period. However, in the final four weeks, S10 increased her involvement in these discussion as the values of betweeness and closeness centrality increased to 16.835 and 0.027 respectively. This confirms that as S10 played a more active role in the discussions, her social role shifted from being a lurker to a gradually mastering member.

Student 5 (S5). For S5, she obtained a betweeness and closeness centrality of 6.925 and 0.029 for the initial four weeks. This indicates that the student was a gradually mastering member. Nevertheless, an increment of between centrality values was observed in the final four week period (37.063). This showed that S5 was very actively involved in discussion among her coursemates and indicates a role change from gradually mastering member to recognized member.

Student 18 (S18). For S18, the betweeness and closeness centrality was 20.177 and 0.026 for the initial four week period indicating that she was a recognized member. In the final four weeks, these values decreased to 0.143 and 0.019 suggesting that she became less active as the semester reached the end. This indicated a shift in roles, where she changed from being a recognized member to a passive member.

Table 4

Betweeness and Closeness Centrality in the Initial Four Week Period

\begin{tabular}{lcccccc}
\hline Vertex & $\begin{array}{c}\text { In- } \\
\text { Degree }\end{array}$ & $\begin{array}{c}\text { Out- } \\
\text { Degree }\end{array}$ & $\begin{array}{c}\text { Betweenness } \\
\text { Centrality }\end{array}$ & $\begin{array}{c}\text { Closeness } \\
\text { Centrality }\end{array}$ & $\begin{array}{c}\text { Eigenvector } \\
\text { Centrality }\end{array}$ & $\begin{array}{c}\text { Clustering } \\
\text { Coefficient }\end{array}$ \\
\hline I1 & 9 & 1 & 8.923 & 0.022 & 0.016 & 0.389 \\
I2 & 14 & 5 & 39.815 & 0.027 & 0.036 & 0.386 \\
I3 & 14 & 7 & 9.857 & 0.028 & 0.040 & 0.400 \\
I4 & 8 & 3 & 11.039 & 0.022 & 0.017 & 0.364 \\
S1 & 3 & 17 & 2.974 & 0.028 & 0.041 & 0.455 \\
S2 & 12 & 5 & 3.202 & 0.026 & 0.035 & 0.460 \\
S3 & 7 & 1 & 0.000 & 0.021 & 0.014 & 0.500
\end{tabular}

This work is licensed under a Creative Commons Attribution 4.0 International License. 


\begin{tabular}{lcccccc} 
S4 & 14 & 4 & 1.721 & 0.026 & 0.037 & 0.467 \\
S5 & $\mathbf{1 8}$ & $\mathbf{3}$ & $\mathbf{6 . 9 2 5}$ & $\mathbf{0 . 0 2 9}$ & $\mathbf{0 . 0 4 1}$ & $\mathbf{0 . 4 2 1}$ \\
S6 & 1 & 24 & 24.814 & 0.032 & 0.046 & 0.360 \\
S7 & 7 & 17 & 16.257 & 0.031 & 0.045 & 0.380 \\
S8 & 8 & 2 & 0.000 & 0.021 & 0.020 & 0.500 \\
S9 & 6 & 14 & 2.974 & 0.028 & 0.041 & 0.455 \\
S10 & 7 & $\mathbf{0}$ & $\mathbf{0 . 0 0 0}$ & $\mathbf{0 . 0 2 0}$ & $\mathbf{0 . 0 1 5}$ & $\mathbf{0 . 5 0 0}$ \\
S11 & 5 & 15 & 2.974 & 0.028 & 0.041 & 0.455 \\
S12 & 9 & 16 & 24.814 & 0.032 & 0.046 & 0.360 \\
S13 & 10 & 16 & 30.735 & 0.033 & 0.047 & 0.346 \\
S14 & 4 & 16 & 8.651 & 0.027 & 0.038 & 0.405 \\
S15 & 12 & 4 & 9.592 & 0.025 & 0.029 & 0.388 \\
S16 & 15 & 1 & 0.000 & 0.025 & 0.034 & 0.500 \\
S17 & 3 & 0 & 0.000 & 0.017 & 0.003 & 0.500 \\
S18 & $\mathbf{1 4}$ & $\mathbf{4}$ & $\mathbf{2 0 . 1 7 7}$ & $\mathbf{0 . 0 2 6}$ & $\mathbf{0 . 0 3 2}$ & $\mathbf{0 . 3 5 6}$ \\
S19 & 8 & 12 & 2.974 & 0.028 & 0.041 & 0.455 \\
S20 & 2 & 22 & 16.257 & 0.031 & 0.045 & 0.380 \\
S21 & 0 & 15 & 0.000 & 0.024 & 0.032 & 0.500 \\
S22 & 15 & 10 & 24.814 & 0.032 & 0.046 & 0.360 \\
S23 & 11 & 13 & 16.257 & 0.031 & 0.045 & 0.380 \\
S24 & 13 & 11 & 16.257 & 0.031 & 0.045 & 0.380 \\
S25 & 12 & 3 & 0.000 & 0.024 & 0.032 & 0.500 \\
\hline Tab & & & & & &
\end{tabular}

Table 5

Betweeness and Closeness Centrality in the Final Four Week Period

\begin{tabular}{lcccccc}
\hline Vertex & $\begin{array}{c}\text { In- } \\
\text { Degree }\end{array}$ & $\begin{array}{c}\text { Out- } \\
\text { Degree }\end{array}$ & $\begin{array}{c}\text { Betweenness } \\
\text { Centrality }\end{array}$ & $\begin{array}{c}\text { Closeness } \\
\text { Centrality }\end{array}$ & $\begin{array}{c}\text { Eigenvector } \\
\text { Centrality }\end{array}$ & $\begin{array}{c}\text { Clustering } \\
\text { Coefficient }\end{array}$ \\
\hline I1 & 8 & 24 & 22.127 & 0.027 & 0.037 & 0.387 \\
I2 & 8 & 11 & 2.197 & 0.02 & 0.024 & 0.493 \\
I3 & 4 & 18 & 6.712 & 0.022 & 0.028 & 0.45 \\
I4 & 16 & 18 & 28.91 & 0.029 & 0.039 & 0.367 \\
S1 & 3 & 11 & 1.092 & 0.019 & 0.018 & 0.513 \\
S2 & 12 & 23 & 26.229 & 0.028 & 0.038 & 0.37 \\
S3 & 13 & 4 & 3.701 & 0.02 & 0.022 & 0.425 \\
S4 & 15 & 7 & 4.04 & 0.023 & 0.031 & 0.478 \\
S5 & $\mathbf{2}$ & $\mathbf{3 2}$ & $\mathbf{3 7 . 6 0 3}$ & $\mathbf{0 . 0 2 9}$ & $\mathbf{0 . 0 4}$ & $\mathbf{0 . 3 5 5}$ \\
S6 & 19 & 8 & 19.57 & 0.026 & 0.035 & 0.403 \\
S7 & 26 & 4 & 16.647 & 0.027 & 0.038 & 0.401 \\
S8 & 6 & 1 & 0 & 0.017 & 0.01 & 0.524 \\
S9 & 7 & 20 & 13.587 & 0.023 & 0.03 & 0.409 \\
S10 & $\mathbf{7}$ & $\mathbf{2 2}$ & $\mathbf{1 6 . 8 3 5}$ & $\mathbf{0 . 0 2 7}$ & $\mathbf{0 . 0 3 8}$ & $\mathbf{0 . 4 0 3}$
\end{tabular}




\begin{tabular}{lcccccc} 
S11 & 13 & 10 & 5.545 & 0.023 & 0.032 & 0.462 \\
S12 & 14 & 21 & 33.51 & 0.029 & 0.039 & 0.36 \\
S13 & 3 & 28 & 26.037 & 0.029 & 0.039 & 0.375 \\
S14 & 9 & 0 & 0 & 0.018 & 0.013 & 0.569 \\
S15 & 15 & 7 & 8.435 & 0.022 & 0.029 & 0.438 \\
S16 & 11 & 18 & 14.381 & 0.025 & 0.034 & 0.405 \\
S17 & 13 & 1 & 0.125 & 0.019 & 0.019 & 0.564 \\
S18 & $\mathbf{1 0}$ & $\mathbf{2}$ & $\mathbf{0 . 1 4 3}$ & $\mathbf{0 . 0 1 9}$ & $\mathbf{0 . 0 1 8}$ & $\mathbf{0 . 5 4 5}$ \\
S19 & 5 & 18 & 13.046 & 0.023 & 0.029 & 0.403 \\
S20 & 13 & 13 & 7.01 & 0.024 & 0.035 & 0.453 \\
S21 & 13 & 16 & 16.409 & 0.025 & 0.034 & 0.395 \\
S22 & 15 & 6 & 0.939 & 0.022 & 0.029 & 0.511 \\
S23 & 20 & 6 & 9.308 & 0.024 & 0.034 & 0.43 \\
S24 & 15 & 6 & 2.437 & 0.022 & 0.029 & 0.484 \\
S25 & 10 & 22 & 19.608 & 0.027 & 0.038 & 0.389 \\
S26 & 13 & 3 & 1.571 & 0.02 & 0.021 & 0.471 \\
S27 & 17 & 0 & 1.715 & 0.02 & 0.024 & 0.496 \\
S28 & 18 & 4 & 2.876 & 0.022 & 0.029 & 0.492 \\
S29 & 6 & 4 & 0 & 0.018 & 0.015 & 0.556 \\
S30 & 17 & 8 & 13.653 & 0.024 & 0.034 & 0.428 \\
\hline
\end{tabular}

\section{Discussion}

The first and second scenarios (lurker to gradually mastering member, and gradually mastering member to recognized member) showed examples of two students gradually becoming active members of the community as the course progressed. In the first scenario, the lurker had a low betweeness and closeness centrality values for the first four weeks indicating that she was not "central" to the learning discussion of the community. Towards the final four weeks of the course, the student gradually mimicked the behavior of the community, thus becoming a gradually mastering member. In the second scenario, the gradually mastering member became a recognized member in the final weeks of the course as the betweeness and closeness centrality values increased. This occurred as the student increased her level of knowledge and skills thus becoming a more active and "central" community member. Both scenarios are in line with the theory of the ladder of participation and mastery by Ryberg and Christiansen (2008), where both students were observed to move up the ladder of participation and mastering as more active roles in the learning community were taken.

Interestingly, in the third scenario, S18 was observed to change into a more passive role indicating that she shifted from being a recognized member to a passive member. Extending the work of Ryberg and Christiansen (2008), this suggest that not only can community members 
move up the ladder of participation and mastering, they can move downwards too (i.e. from a recognized member to a passive member state). From these findings, we propose a "continuum for roles of social participation in mobile social media learning" as illustrated in Figure 5. The continuum consists of four roles. The four social roles are: (i) lurker; (ii) gradually mastering member or passive member; (iii) recognized member; and (iv) coach. The continuum is bidirectional, where roles on the left represent a lower centrality in participation and on the right represent a higher centrality.

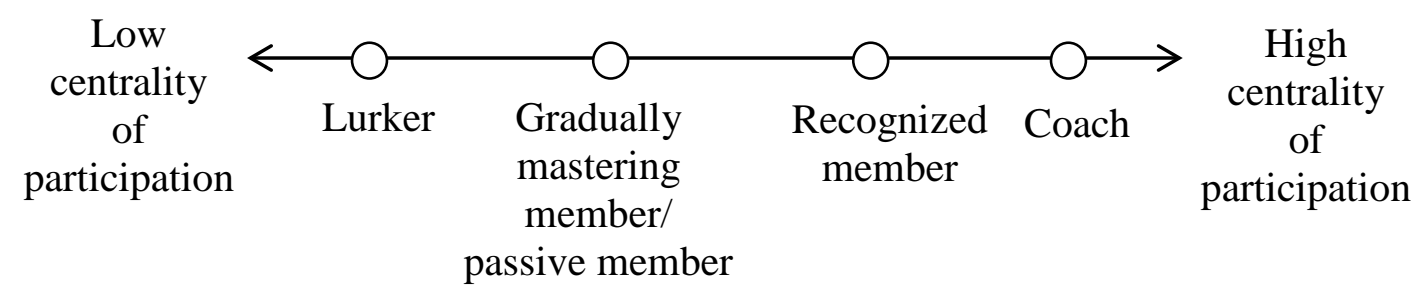

Figure 5. Proposed continuum for roles of social participation in mobile social media learning.

In relation, three scenarios discussed could have been influenced by the following factors: (i) structure of the learning tasks; (ii) interpersonal relationships; and (iii) role of course coordinators.

\section{Structure of Learning Tasks}

For structure of learning tasks, the learning tasks which were given to the students were unstructured (loosely structured). Towards the end of the course, S5 and S10 assumed more active roles for this type of learning task, while S7 became more passive. For S7, such tasks that lack "structure" or "certain pathways" may have caused the student to feel "disoriented" or "lost" and lead to the increased level of passiveness. Although a general learning task was set (i.e. production of a video on an open topic with mobile devices), specific learning tasks or structure were not given to students for completion of their learning task. S7 may have preferred more structure in learning whereas S5 and S7 may have preferred learning with less structure. With respect to this, a structured learning task could be useful when there is fixed learning goal. Nievelstein, Van Gog, Van Dijck \& Boshuizen (2013) reported that novice learners worked better with learning problems that are more tightly structured rather than loose ones due to the fact that tightly structured problems were harder to master. On the contrary, structured problems usually involve lower-order thinking tasks where in most cases, the objective of learning would be in achieving a higher thinking order (King, 2008). This could be implemented by using unstructured learning problems where high-order skills such as reflection would be required to complete learning tasks. Nevertheless, as unstructured learning tasks would have less structure, there is a possibility for students to become "disoriented" or "lost" without proper guidance from instructors or peers (Kop, Fournier, \& Mak, 2011; Fewkes \& McCabe, 2012; Mackness, Waite, Roberts, \& Lovegrove, 2013). This poses an interesting question as to whether learners should be 
given full autonomy over learning or not and whether certain level of structure is important to guide learners in the learning process.

\section{Interpersonal Relationships}

Interpersonal relationships may have also contributed to the increase and decrease of activity among the students. As S5 and S7 became more active towards the final four weeks, this could have been prompted by the increased interpersonal relationships built among the other coursemates - making them more central members of the learning community. This may also have been related to their "sense of belonging" to the community which was cultivated towards the end of the course. This could be linked to findings of Kabilan, Ahmad, \& Abidin (2010). They discovered that Facebook can promote a "sense of belonging" among learners due to the fact that the platform was used to share their thoughts and feelings on their own work as well as their peers' work. In contrast, S18 became more passive in the final weeks. As S5 and S10 may have regarded the Facebook Group platform as a medium for them to enhance their learning in the learning community, S18 may have perceived Facebook not suitable for learning. In study on the effects of using Facebook as an LMS, Wang, Woo, Quek, Yang, \& Liu (2012) reported that learners raised some concerns on Facebook as a learning tool. Although learners regarded Facebook as an important tool for communication and social interaction in Wang et al.'s (2012) study, they perceived that Facebook was not suitable a suitable tool for formal learning. Thus, this concern warrants future investigation as to whether Facebook is an appropriate tool for learning.

\section{Role of Course Coordinators}

Another factor that may have contributed is the role of course coordinators. In final four weeks, S5 and S7 played central roles in the learning community, whereas S18 played a passive one. Due to the fact the tasks given were unstructured, the role of course coordinators changed, where they became more of a facilitator of learning rather than an instructor or teacher. As this occurred, the level of moderation of discussions among students was observed to decrease as the coordinators attempted to promote self-initiation of discussions among them. This could have impacted S18, where she could have preferred a higher level of moderation from the course coordinators as in traditional learning environments. This scenario can be linked to Thormann, Gable, Fidalgo, \& Blakeslee's (2013) work where they studied students as student moderators in social media. They reported that appointment of student as moderators could potentially assist to promote a sense of community among the students. In addition, they also found out that this type of moderation can encourage student ownership of their own learning content thus increasing participation in the discussions as well as broadening the scope of the discussion. In the context of this study, S5 and S7 could have assumed the role of student moderators in the discussion which took place in the final weeks while S18 could have preferred more moderation from course coordinators instead of her peers, hence leading to the decrease in her online discussion involvement. Thus, this poses another interesting question for future research as to whether moderation should be assumed by course coordinators/instructors or students.

This work is licensed under a Creative Commons Attribution 4.0 International License. 


\section{Conclusion and Implications}

The study is an extension of Ryberg and Christiansen's (2008) work where two conclusions can be drawn. First, the study has discovered that there is a new social participation role in mobile social media learning which is "passive members". Second, the findings have also revealed that role shifts of social participation can occur in a period of four months, where a student can become more central and active in learning discussions or become more less central and passive the discussions. In other words, not only can a student move up the "ladder of participation and mastering" in mobile social media learning, they also can move down into a more passive state of social participation. As such, a continuum for roles of social participation in mobile social media learning is proposed.

Although the study has revealed some interesting perspectives on mobile social media learning, some limitations should be kept in mind. First, the study only investigated roles of social participation based on the "ladder of participation and mastering" by Ryberg and Christiansen (2008). Adapting other participation models or frameworks could yield in different results. Second, learning was studied from a learner perspective. Role of instructors were not investigated. Third, only unstructured learning tasks were studied. It would be interesting to identify roles of social participation in semi-structured and fully-structured learning tasks. The level of structure could reveal different roles associated to social participation for mobile social media learning. Fourth, the study was conducted in an educational technology course at a local university. Geographical and cultural aspects may have influenced the results.

In sum, the research findings could be useful for future research in the fields of curriculum development, teaching and learning in mobile social media, and social media interface design. For curriculum development, the research findings could be used to design learning tasks in mobile social media that can promote high centrality of participation among learners. In terms of teaching and learning, the results can be used as a means of identifying active and passive learners in unstructured learning environments. Upon identification of active/ passive learners, instructors could design effective learning interventions to guide discussions towards meaningful discussion for learning. As for social media interface design, interface designers could use the research results to develop better interfaces and automated triggers that can promote learning in mobile social media learning. Effective automated triggers could be useful in enhancing learning via mobile social media.

This work is licensed under a Creative Commons Attribution 4.0 International License. 


\section{References}

Aadal, L., Kirkevold, M., \& Borg, T. (2013). Neurorehabilitation analyzed through 'situated learning' theory. Scandinavian J ournal of Disability Research (ahead-of-print), 1-16.

Ali, R., J iang, N., \& Dogan, H. (2013). Socially-augmented software: Empowering software operation through social contacts. In: The Third IEEE International Conference on Cloud and Green Computing 2013 (pp. 404-409).

Ally, M., \& Samaka, M. (2013). Open education resources and mobile technology to narrow the learning divide. The International Review of Research in Open and Distance Learning, 14(2), 14-27.

Bandura, A. (1977). Social Learning Theory. Englewood Cliffs, NJ : Prentice Hall.

Bechmann, A., \& Lomborg, S. (2013). Mapping actor roles in social media: Different perspectives on value creation in theories of user participation. New media \& society, 15(5), 765-781.

Caspi, A., Chajut, E., Saporta, K., \& Beyth-Marom, R. (2006). The influence of personality on social participation in learning environments. Learning and Individual Differences, 16(2), 129-144.

Chen, B., \& Bryer, T. (2012). Investigating instructional strategies for using social media in formal and informal learning. The International Review of Research in Open and Distributed Learning, 13(1), 87-104.

Chin, A., \&Zhang, D. (2014). Mobile Social Networking. New York: Springer.

Cochrane, T., \& Bateman, R. (2010). Smartphones give you wings: Pedagogical affordances of mobile Web 2.0. Australasian J ournal of Educational Technology, 26(1).

Dabbagh, N., \& Kitsantas, A. (2012). Personal learning environments, social media, and selfregulated learning: A natural formula for connecting formal and informal learning. The Internet and Higher Education, 15(1), 3-8.

De Laat, M., Lally, V., Lipponen, L., \& Simons, R. J . (2007). Investigating patterns of interaction in networked learning and computer-supported collaborative learning: A role for Social Network Analysis. International J ournal of Computer-Supported Collaborative Learning, 2(1), 87-103.

Fewkes, A. M., \& McCabe, M. (2012). Facebook: Learning tool or distraction? J ournal of Digital Learning in Teacher Education, 28(3), 92-98.

This work is licensed under a Creative Commons Attribution 4.0 International License. 
Gikas, J ., \& Grant, M. M. (2013). Mobile computing devices in higher education: Student perspectives on learning with cellphones, smartphones \& social media. The Internet and Higher Education, 19, 18-26.

Harel, D., \& Koren, Y. (2001). A fast multi-scale method for drawing large graphs. In Graph drawing (pp. 183-196). Springer Berlin Heidelberg.

Hansen, D., Shneiderman, B., \& Smith, M. A. (2010). Analyzing social media networks with NodeXL: Insights from a connected world. Morgan Kaufmann.

J eng, Y. L., Wu, T. T., Huang, Y. M., Tan, Q., \&Yang, S. J . (2010). The add-on impact of mobile applications in learning strategies: A review study. Educational Technology \& Society, 13(3), 3-11.

Kabilan, M. K., Ahmad, N., \&Abidin, M. J . Z. (2010). Facebook: An online environment for learning of english in institutions of higher education? The Internet and Higher Education, 13(4), 179-187.

King, A. (2008). Structuring peer interaction to promote higher-order thinking and complex learning in cooperating groups. In The teacher's role in implementing cooperative learning in the classroom (pp. 73-91).

Kop, R., Fournier, H., \& Mak, J . S. F. (2011). A pedagogy of abundance or a pedagogy to support human beings? Participant support on massive open online courses. The International Review Of Research In Open And Distributed Learning, 12(7), 74-93.

Kopcha, T. J ., \&Alger, C. (2014). Student teacher communication and performance during a clinical experience supported by a technology-enhanced cognitive apprenticeship. Computers \& Education, 72, 48-58.

Knobelsdorf, M., Kreitz, C., \& Böhne, S. (2014). Teaching theoretical computer science using a cognitive apprenticeship approach. In Proceedings of the 45th ACM Technical Symposium on Computer Science Education (pp. 67-72).

Kukulska-Hulme, A. (2010). Learning cultures on the move: Where are we heading? J ournal of Educational Technology and Society, 13(4), 4-14.

Kuo, F. R., Hwang, G. J ., Chen, S. C., \& Chen, S. Y. (2012). A cognitive apprenticeship approach to facilitating web-based collaborative problem solving. Educational Technology \& Society, 15(4), 319-331.

Lave, J ., \&Wenger, E. (1991). Situated learning: Legitimate peripheral participation. Cambridge: Cambridge University Press. 
Lewis, S., Pea, R., \& Rosen, J . (2010). Beyond participation to co-creation of meaning: Mobile social media in generative learning communities. Social Science Information, 49(3), 351369.

Liu, T. C., Lin, Y. C., Tsai, M. J., \&Paas, F. (2012). Split-attention and redundancy effects on mobile learning in physical environments. Computers \& Education, 58(1), 172-180.

Mackness, J., Waite, M., Roberts, G., \&Lovegrove, E. (2013). Learning in a small, task- oriented, connectivist MOOC: Pedagogical issues and implications for higher education. The International Review of Research in Open and Distance Learning, 14(4).

Naismith, L., Sharples, M., Vavoula, G., \&Lonsdale, P. (2004). Literature review in mobile technologies and learning. Birmingham: Future Labs.

Ni, C., Sugimoto, C., \&J iang, J . (2011). Degree, closeness, and betweenness: Application of group centrality measurements to explore macro-disciplinary evolution diachronically. In Proceedings of ISSI (pp. 1-13).

Nievelstein, F., Van Gog, T., Van Dijck, G., \& Boshuizen, H. P. (2013). The worked example and expertise reversal effect in less structured tasks: Learning to reason about legal cases. Contemporary Educational Psychology, 38(2), 118-125.

Norman, H., Din, R., Nordin, N., \& Ryberg, T. (2014). A review of the perceived use and effects of mobile blogs in higher educational settings. Asian Social Science, 10(1): 209-222.

Park, Y. (2011). A pedagogical framework for mobile learning: Categorizing educational applications of mobile technologies into four types. The International Review of Research in Open and Distributed Learning, 12(2), 78-102.

Pimmer, C., Linxen, S., \& Gröhbiel, U. (2012). Facebook as a learning tool? A case study on the appropriation of social network sites from mobile phones in developing countries. British J ournal of Educational Technology, 43(5), 726-738.

Ryberg, T., \& Christiansen, E. (2008). Community and social network sites as technology enhanced learning environments. Technology, Pedagogy and Education, 17(3), 207-219.

Ryberg, T., Glud, L. N., Buus, L., \& Georgsen, M. (2010). Identifying differences in understandings of PBL, theory and interactional interdependencies. In Networked Learning Conference 2010 (pp. 943-951).

Siemens, G., \&Weller, M. (2011). Higher education and the promises and perils of social network. Revista de Universidad y Sociedad del Conocimiento (RUSC), 8(1), 164-170.

This work is licensed under a Creative Commons Attribution 4.0 International License. 
Sharples, M., Taylor, J ., \& Vavoula, G. (2010). A theory of learning for the mobile age. In Medienbildung in neuen Kulturräumen (pp. 87-99). VS Verlag für Sozialwissenschaften.

Thormann, J ., Gable, S., Fidalgo, P. S., \& Blakeslee, G. (2013). Interaction, critical thinking, and social network analysis (SNA) in online courses. The International Review of Research in Open and Distance Learning, 14(3), 294-318.

Wang, Q., Woo, H. L., Quek, C. L., Yang, Y., \& Liu, M. (2012). Using the facebook group as a learning management system: An exploratory study. British J ournal of Educational Technology, 43(3), 428-438.

Wong, L. H. (2012). A learner-centric view of mobile seamless learning. British J ournal of Educational Technology, 43(1), E19-E23.

Wenger, E. C., White, N., \& Smith, J . D. (2009). Digital habitats: Stewarding technology for communities. Portland, Oregan: CPsquare.

Zheng, B., Niiya, M., \&Warschauer, M. (2015). Wikis and collaborative learning in higher education. Technology, Pedagogy and Education, (ahead-of-print), 1-18.

(c) Norman, Nordin, Din, Ally, and Dogan

\section{Athabasca University $\mathbf{I}$}

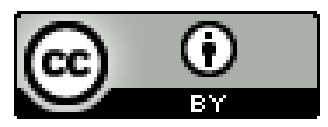

